\title{
Distilled water and ethyl alcohol boiling heat transfer on selected meshed surfaces
}

\author{
Lidia Dąbek ${ }^{1}$, Andrej Kapjor ${ }^{2}$, and Łukasz J. Orman ${ }^{1, *}$ \\ ${ }^{1}$ Kielce University of Technology, Faculty of Environmental, Geomatic and Energy Engineering, al. Tysiaclecia P.P.7, \\ 25-314 Kielce, Poland \\ ${ }^{2}$ University of Zilina, Faculty of Mechanical Engineering, Univerzitna 1, 01026 Zilina, Slovakia
}

Received: 27 March 2019 / Accepted: 5 October 2019

\begin{abstract}
The article deals with the problem of pool boiling heat transfer enhancement on metal wire mesh coatings made of copper and phosphor bronze at nucleate boiling of distilled water and high purity ethyl alcohol under ambient pressure. The tests have been performed on horizontal samples containing different microstructures produced with the sintering technology. The samples were attached to the heating block with soldering. As a result of the experiments, boiling curves were obtained, describing the relationship between the dissipated heat flux and the superheat values for each specimen. A considerable augmentation of heat flux has been recorded for the meshed surfaces in relation to the smooth reference surface without any coating. Generally, the highest enhancement was recorded for the low superheat values. The presented test results have been discussed and then compared with selected correlations available in literature for nucleate boiling heat transfer on microstructure coated surfaces.
\end{abstract}

Keywords: Boiling / heat transfer enhancement / meshes

\section{Introduction}

Nucleate boiling heat transfer is a phase - change process characterised by significant values of heat fluxes being exchanged at low temperature differences. The devices utilising this mode of heat transfer have very broad applications in the industry, for example in refrigeration and air conditioning systems as well as for electronics' cooling. Heating surfaces can be smooth, but the additional increase in the exchanged heat flux values may be obtained if special microstructures are applied onto the surfaces of heat exchangers. These coatings include, among others: metal wire meshes, metal - fibrous structures, sintered powders as well as other specially treated surfaces. Even roughening of the surface has a positive impact on the heat flux. The coatings generally tend to elevate heat fluxes in comparison to the smooth surfaces at the same superheats (or transfer the same heat flux at much lower temperature difference), however, in some cases it is possible to obtain lower values than those recorded for the smooth surface.

Poniewski [1] presented a comprehensive overview of coatings that may lead to increased heat flux values dissipated during boiling. Heat flux enhancement has been

\footnotetext{
* e-mail: orman@tu.kielce.pl
}

attributed to be the result of a modification of the surface microstructure so that the number of active nucleation sites rises and the stabilised operation of these sites is ensured. The special coatings for boiling heat transfer enhancement include: sintered or thermally sprayed powder microstructures, metal - fibrous coatings, wire meshes, industrially made microstructures, and coverings made using the combination of the above mentioned methods. Industrially produced surfaces could be made with different techniques (e.g. sintered metal elements, microfins, plasma and flame sprayed coatings, etc.) and are often patented.

Among many commercially and non-commercially available microstructures highly effective are wire metal coatings, which are the focus of attention in the current paper. These structures are inexpensive to make and are widely available because of their application possibilities in other areas of engineering. For example, they can be used for the production of sieves or heat pipes [2].

Sasin et al. [3] investigated water, ethanol and ether boiling heat transfer on mesh coated heaters in the form of heat pipes. The material of the meshes was brass and stainless steel. The coatings have been attached mechanically onto the surface. The authors reported that for a given number of mesh layers there is an optimal aperture (distance between the wires) for which the maximal value 
of the critical heat flux is obtained. Smirnov et al. [4] tested copper and brass meshes applied mechanically to the heaters. The working agents were water and ethanol. It was reported that the value of heat flux was generally independent of the structure height (number of layers) and weakly dependent on the kind of material. Rannenberg and Beer [5] considered boiling of refrigerant agents R-11 and R-113 on a horizontal heater, on which two to nine layers of mesh were applied. The material of the coatings ware stainless steel and bronze. It was concluded that the structure height (the number of mesh layers) had no impact on boiling heat transfer.

Tolubinskij et al. [6] experimentally tested water boiling on a heater, on which a single layer of stainless steel mesh had been mechanically applied. It was found out that the phenomenon of heat transfer on single mesh layers depends on the value of the mesh aperture in relation to the bubble departure diameter. The article by Tsay et al. [7] covers the experimental work on water boiling on a smooth and rough heater surface with a single stainless steel mesh layer. The conducted visualisation studies enabled to conclude that the number of vapour bubbles grown on the heater with the additional coating was higher than on the smooth surface.

Brausch and Kew [8] considered water boiling heat transfer on a surface, on which one, three and five mesh layers were applied. It was given that one mesh layer augmented boiling in relation to the smooth reference surface at low superheat values (up to fifteen Kelvin). This finding was explained by the creation of additional nucleation sites on the surface. For small superheat values the enhancement was most considerable for meshes of smaller apertures. Based on the visualisation studies, it was reported that the rate of bubble production at small superheat values (up to ten Kelvin) was higher on surfaces with a single layer. In the case of larger superheats the microstructure made the removal of vapour from the coating more difficult.

One of few works on boiling on non-isothermal surfaces has been the one by Orzechowski [9], who tested copper meshes (one, two and three layers of mesh) sintered the vertical fin under distilled water boiling. It was found out that the use of the microstructure increased heat flux in relation to the smooth surface without any coating, but the enhancement observed between the layers of two and three meshes was not very significant.

Li et al. [10] gave four reasons why boiling heat transfer may be enhanced due to the use of microstructural coatings. One of them is higher number of active nucleation sites (locations where bubbles are grown) and extension of the surface for effective evaporation.

Liou et al. [11] experimentally analysed porous coatings made of copper meshes sintered to the surface of heat pipes. It was reported that as the heat load was increasing, water film receded to form corrugated menisci within the considered layer and evaporation resistance became lower until partial dryout took place. A development on the use of meshes has been very recently proposed by Pastuszko [12], who investigated structures made of microfins and meshes sintered to them for further boiling heat transfer enhancement.
Because the use of microstructure coated heaters can provide considerable enhancement of boiling heat transfer, more experimental data is necessary to be obtained in this area. It is especially important due to the fact that phase change heat exchangers are found in many industrial applications (e.g. in refrigeration or air conditioning systems, high performance cooling devices, etc. - including flow boiling, as described in [13]).

\section{Materials and method}

The tests have been focused on the performance of copper and phosphor bronze meshes applied on the horizontal heater of $3 \mathrm{~cm}$ diameter. The aperture of the meshes ranged from $0.20 \mathrm{~mm}$ to $1.5 \mathrm{~mm}$, while wire diameter from $0.12 \mathrm{~mm}$ to $0.32 \mathrm{~mm}$. The boiling agents have been distilled water and ethyl alcohol (99.8\% purity), tested under ambient pressure. The production of samples involved the sintering process - the meshes and copper bases (discs of $2 \mathrm{~mm}$ height) were sintered to each other in the atmosphere of hydrogen and nitrogen. This process occurs at the temperature which is slightly lower than the melting temperature. As a result strong bonds between the joined elements can be developed. The wires of the mesh and the base surface of the heated are almost molten into one another. Thus, thermal resistance is minimised and the obtained heat exchanger can be very efficient for heat transfer.

Figure 1 presents a $3-\mathrm{D}$ image of the sample produced with a bronze mesh of aperture $0.20 \mathrm{~mm}$ and wire diameter of $0.12 \mathrm{~mm}$ together with the cross - section element provided as a surface profile in Figure 2.

The tests were carried out on the experimental stand, which is mainly made of the heater block (a copper element, on which the sample is soldiered, while inside it an electric heater is located), the glass tube combined with the cooler and the data reduction equipment. Boiling takes place within the glass tube that contains the sample and the liquid agent. The cooling coil enables to recover the evaporated material, which is flown back to the glass tube. The heater has been shown in Figure 3 together with the location of thermocouples. In order to produce boiling curves, which provide information on the performance of each sample, the power supplied to the heater was raised with the use of an autotransformer with certain steps. After each power change measurements were made only after the conditions stabilised.

The end result of each test was a boiling curve. It presented the dependence of heat flux (or heat transfer coefficient) vs. wall superheat (a difference between the wall and the liquid saturation temperatures). The determination of heat flux was done with the use of temperature data from the thermocouples located in the axis of the heating block, the distance between them and the thermal conductivity of copper). Temperature values below the specimens were recorded, too. This enabled to determine the temperature on the surface and, consequently, provide necessary data to draw the boiling curves. The stand was properly insulated using high temperature fibre insulation, while the samples were surround with the 


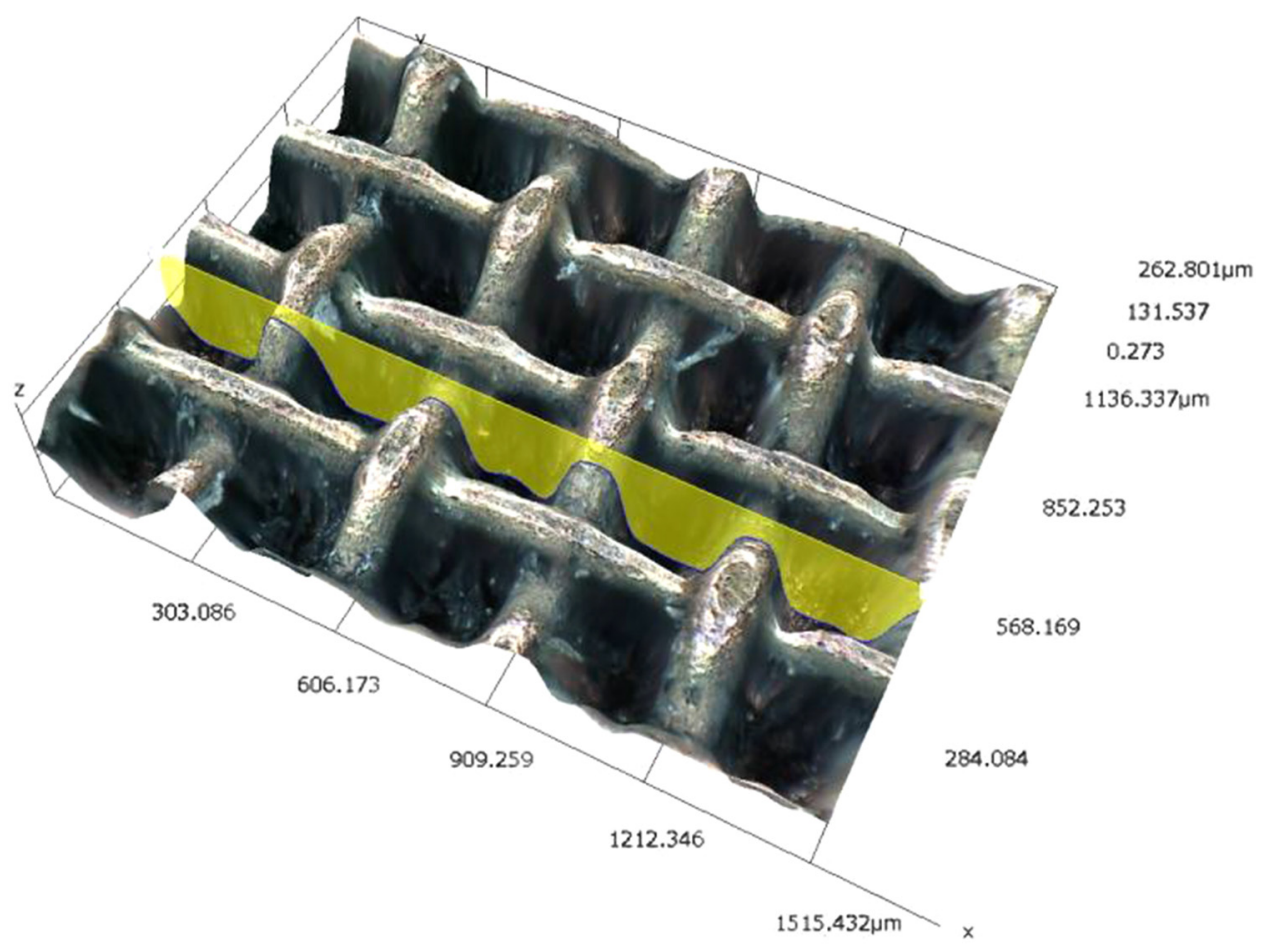

Fig. 1. The 3-D microscopic image of the bronze sample (aperture $0.20 \mathrm{~mm}$, wire diameter $0.12 \mathrm{~mm}$ ).

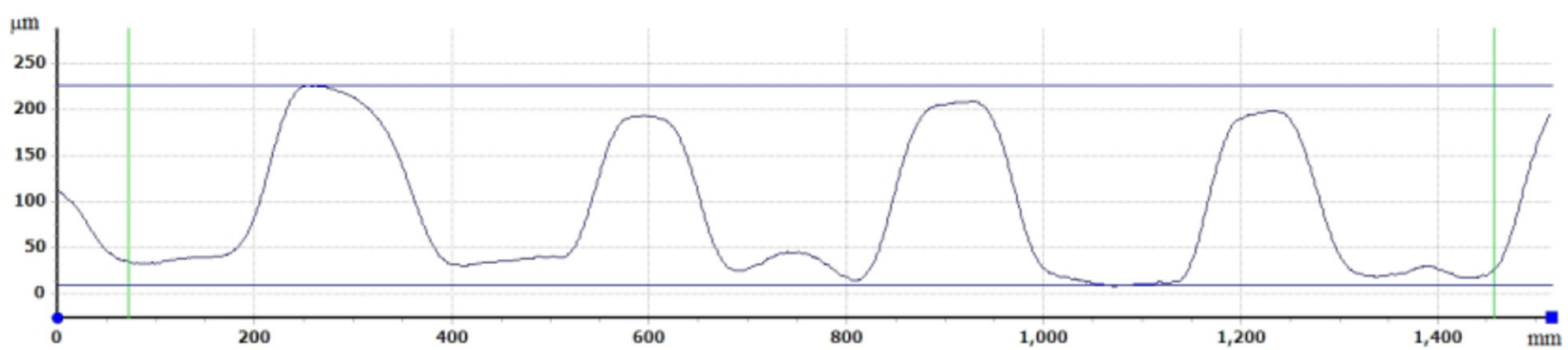

Fig. 2. Surface profile of the sample from Figure 1.

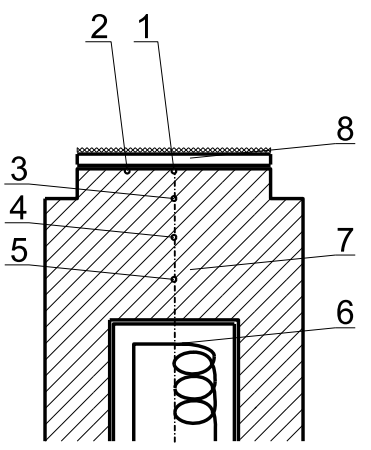

Fig. 3. The main element of the experimental stand: 1, $2-$ thermocouples below the soldiered sample, 3, 4, 5- thermocouples in the axis of the heating block, 6 - electric resistance heater, 7 - copper block, 8 - specimen with the mesh [14]. teflon plate. A digital multimeter combined with a computer was used for data acquisition. Apart from the temperature readings from below the samples, also saturation temperature was measured. Only $\mathrm{K}$ type thermocouples were used in the experiments.

\section{Test results and discussion}

The experiments have been performed within nucleate boiling regime because of the highest applicability of the produced results in this mode of heat transfer. The liquids used in the study are distilled water and ethyl alcohol of very high purity (99.8\%). The results have been given below in the form of the boiling curves with the smooth surface data (a copper heater disc with no additional coating) presented for reference. 


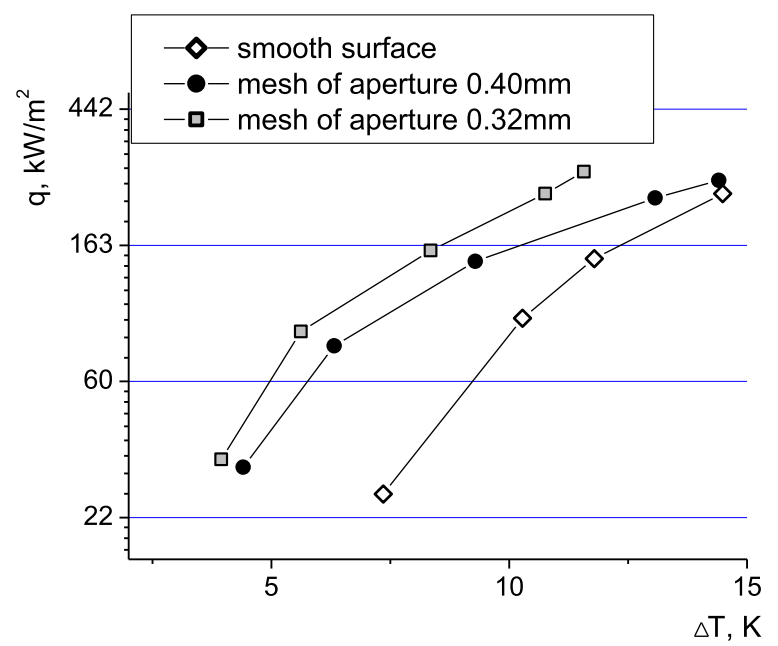

Fig. 4. Boiling curves for phosphor bronze meshes of different apertures [15], boiling agent: distilled water.

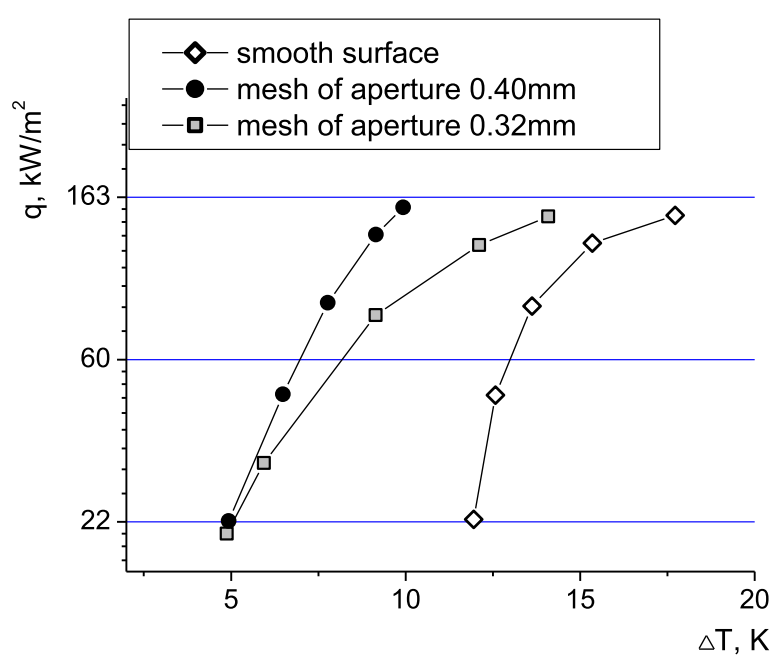

Fig. 5. Boiling curves for phosphor bronze meshes of different apertures [15], boiling agent: ethyl alcohol.

The impact of the value of mesh aperture on boiling heat transfer of the considered boiling agents has been shown in Figures 4 and 5 - as already presented by the authors in the conference paper [15]. The diameter of the wires in the case of both phosphor bronze meshes was $0.20 \mathrm{~mm}$, while the aperture values of these meshes were $0.32 \mathrm{~mm}$ and $0.40 \mathrm{~mm}$. The calculated surface porosity of the microstructures was $38 \%$ and $44 \%$, respectively. The experiments were performed for layers containing one mesh applied onto the heater. The data regarding the smooth surface and the phosphor bronze mesh of the aperture $0.40 \mathrm{~mm}$ was given by the author in [14].

The influence of the value of aperture is clearly visible from the above figures. The highest enhancement of boiling heat transfer was recorded for the mesh of the smaller aperture. This is very easily noticed in the case of distilled water. In terms of the performance of meshes with ethyl

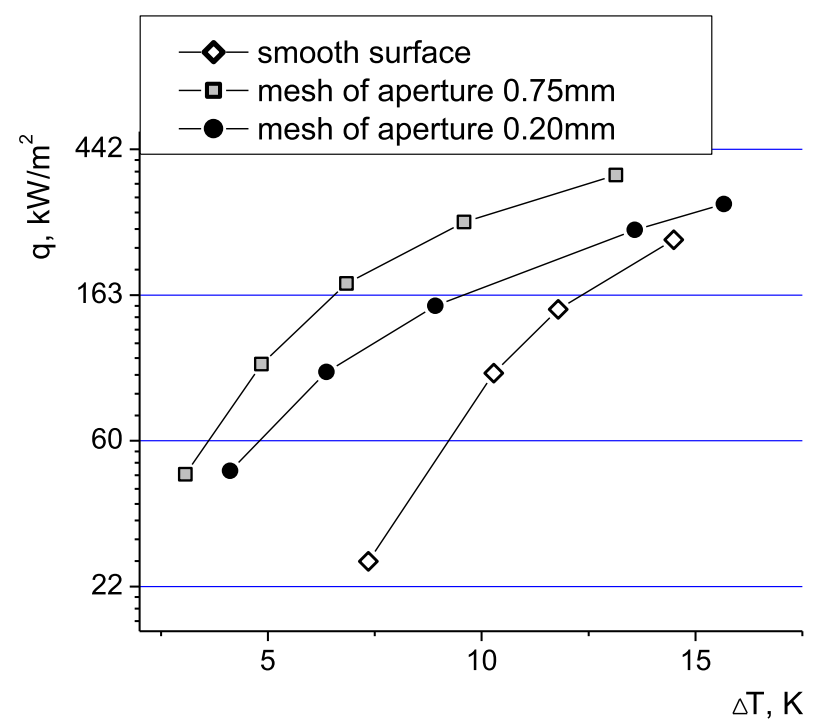

Fig. 6. Boiling curves for meshes of significantly different apertures; boiling agent: distilled water.

alcohol boiling, the obtained results for the mesh of $0.32 \mathrm{~mm}$ aperture are also better, however the influence is much more considerable for high superheat values. In the case of low superheats of about five Kelvin the test results prove to be very similar.

It indicates that smaller apertures provide better conditions for bubble growth for the considered boiling liquids. The vapour bubbles are produced at nucleation sites located between the mesh wires. Higher density of such active nucleation sites leads to more bubbles being grown. Consequently, heat transfer is improved. Nevertheless, the literature provides examples that in the case of very small aperture values heat exchange becomes weaker. Thus, this phenomenon has to be analysed considering the diameter of the produced vapour bubbles (ethanol boiling produces bubbles of smaller diameter than distilled water boiling). In order to analyse this phenomenon, a comparison of two other, single layer meshes, has been done. One mesh has a large aperture $(0.75 \mathrm{~mm})$, while the other much smaller $(0.20 \mathrm{~mm})$ - the image of the fine mesh of $0.20 \mathrm{~mm}$ aperture has been shown in Figure 1. The results of heat flux determination have been presented in Figures 6 and 7 for both boiling liquids.

Undoubtedly, the application of the finest mesh (of the smallest aperture of $0.20 \mathrm{~mm}$ ) provided the weakest improvement in heat flux. It is especially visible in the case of water. Here, the values of heat flux for high superheats are almost identical to those recorded for the smooth surface. It might be linked with the production of large amounts of vapour at high heat fluxes. The generated vapour might be blocked within the mesh (the flow of vapour out of the mesh and liquid into the microstructure is hampered). The phenomenon is much less visible in the case of ethanol. It might be explained by a significantly lower vapour production and smaller bubble diameters for ethyl alcohol. In this case the highest enhancement occurs for low superheats. Here, the density of nucleation sites for the finest mesh is highest and, due to the small diameter of 


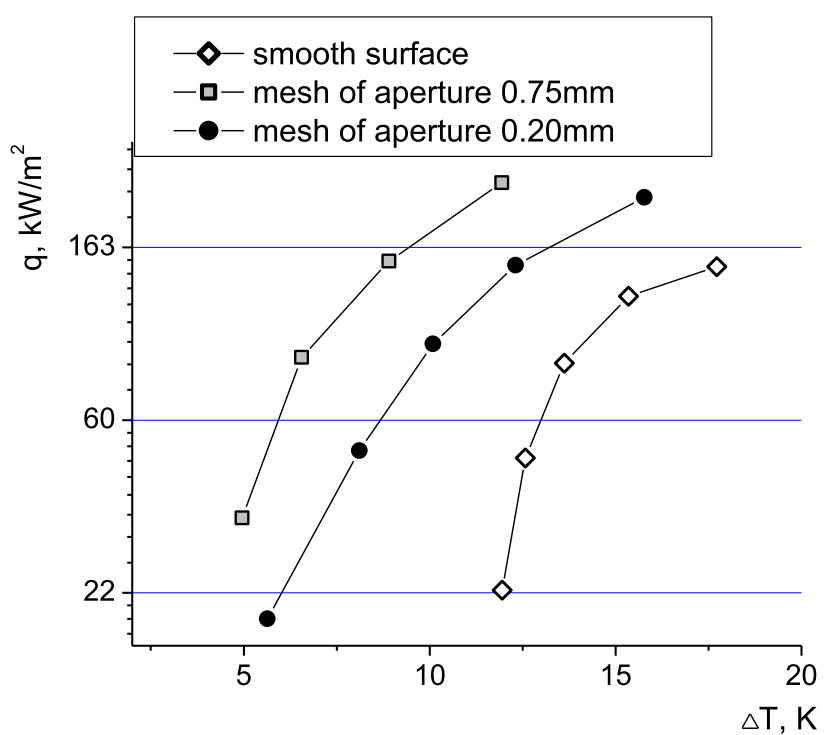

Fig. 7. Boiling curves for meshes of significantly different apertures; boiling agent: ethyl alcohol.

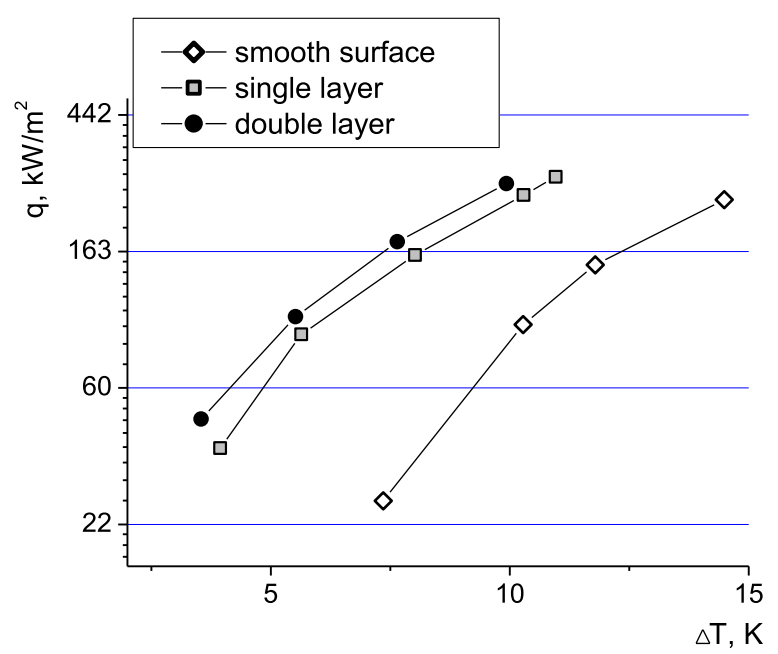

Fig. 8. Boiling curves for single and double mesh layers; boiling agent: distilled water.

the generated bubbles, more of them are active then in the case of water. Thus, the heat flux is enhanced.

Nucleate boiling heat transfer might also be affected by the number of mesh layers sintered to the heater, although the reports in literature are often contradictory. Figures 8 and 9 show the boiling curves for two types of meshed surfaces: single layer and double layer, made of copper meshes of aperture $1.50 \mathrm{~mm}$ and wire diameter $0.32 \mathrm{~mm}$.

As can be seen in the above figures, the use of multilayer meshes might not be very advantageous. The results of ethyl alcohol boiling prove no influence of the additional mesh layer on heat flux. In the case of water there is a slight enhancement caused by adding another mesh onto the heater, although the character of the boiling phenomenon remains the same (the heat flux values are just shifted vertically). The discrepancy of the performance of the

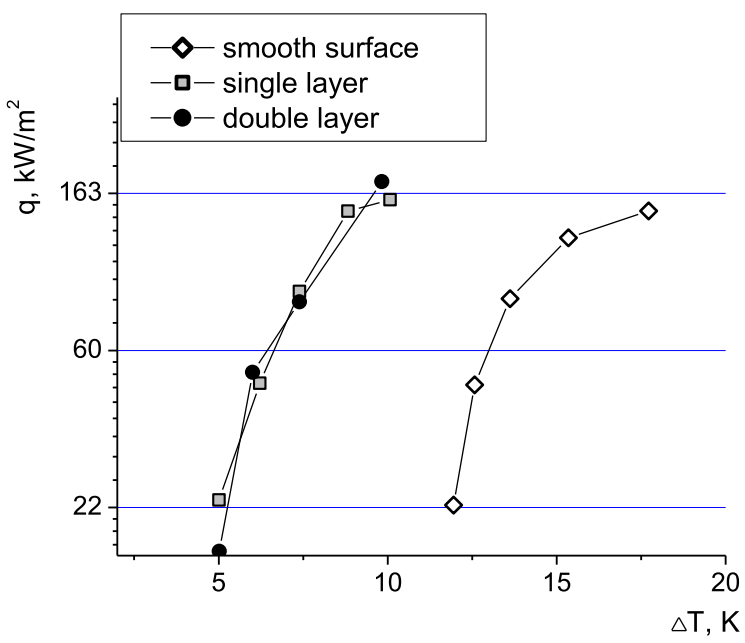

Fig. 9. Boiling curves for single and double mesh layers; boiling agent: ethyl alcohol.

microstructure covered heaters for both the liquids might be related to the fact that the additional layer increases the density of active nucleation sites, which is vital for distilled water, while in the case of ethyl alcohol (where vapour bubbles are much smaller) this density is not affected. It stems from the fact that the mesh aperture is large $(1.5 \mathrm{~mm})$ and bubbles of ethanol vapour are generated on the smooth surface between the wires. In this case the application of mesh may only extend the surface, but offers no other advantage.

The results of the experimental tests also prove that the largest impact of the use of the mesh is in the region of low superheat values. For larger temperature differences data points may approach the values obtained for the smooth reference surface. This phenomenon can be explained by the fact that due to higher vapour generation inside the porous microstructure a problem to sustain the efficient vapour removal from the coating and liquid transport to it may occur. Here the transition boiling heat transfer mode might take place.

The graphic presentation of the enhancement produced with the mesh coatings studied in the paper can be seen in Figure 10. It covers data for the large and small aperture values. The considered 'enhancement ratio' given in the figure is the ratio of the heat flux transferred from the meshed surface to the heat flux removed from the smooth reference surface for the same value of superheat. The input data to draw the curves were taken from Figure 6 for distilled water boiling. The necessary calculations required generation of the polynomial fits of the second order of the considered test results (for the meshed and smooth surfaces). This resulted in producing the curves presented below.

The application of the additional coating in form of the mesh turned out to be most effective in the region of low superheat values. Here, heat flux transferred from the meshed surface (of $0.75 \mathrm{~mm}$ aperture) was over seven times higher than for the smooth reference surface. For larger temperature differences this effect diminished for both the meshes, however, the performance of the finest mesh 


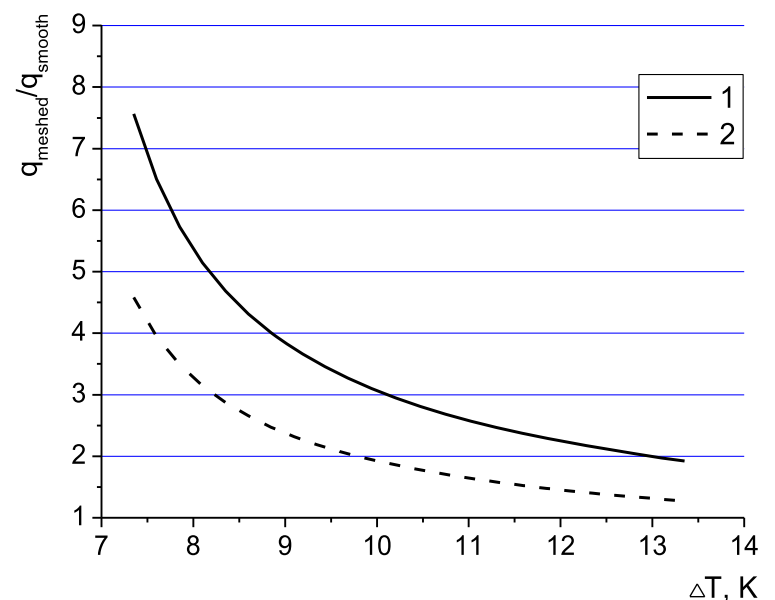

Fig. 10. Enhancement ratio of the meshed surfaces covered with meshes of different values of aperture $(1$ - aperture of $0.75 \mathrm{~mm}$, 2 - aperture of $0.20 \mathrm{~mm}$; data from Fig. 6).

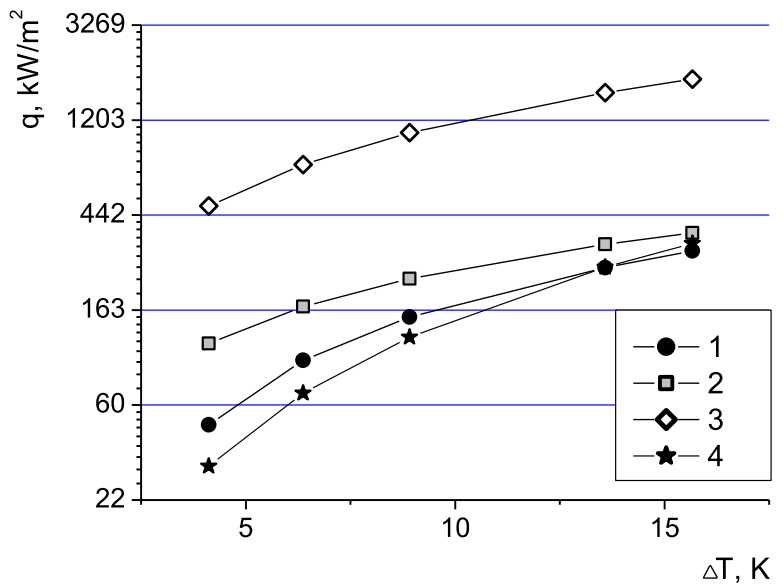

Fig. 11. Comparison of the experimental data (1) with the calculation results according to the correlations: Smirnov et al. (2), Nishikava et al. (3), Xin and Chao (4); bronze mesh $0.20 \mathrm{~mm}$ $\times 0.12 \mathrm{~mm}$, boiling agent: distilled water.

(of $0.20 \mathrm{~mm}$ aperture) was only slightly better then in the case of the smooth surface.

A theoretical modeling of boiling on microstructure coated surfaces is a different and complicated problem. However, it is vital for the proper design of heat exchangers. Data presented for the mesh of aperture $0.20 \mathrm{~mm}$ (of wire diameter $0.12 \mathrm{~mm}$, volumetric porosity $67 \%$, made of bronze) has been compared with selected correlations from literature, namely those developed by Smirnov et al. [4,16,17], Nishikava et al. [18] as well as Xin and Chao [19].

Performing calculations using the model by Xin and Chao, required the introduction of certain modifications regarding geometrical parameters present in the formulae. The single cell's width was considered as the total of wire diameter and aperture, while the width of the tunnel as aperture. The end results of the performed calculations have been presented in Figures 11 and 12 for distilled water and ethyl alcohol, respectively and compared with the experimental values from Figures 6 and 7 .

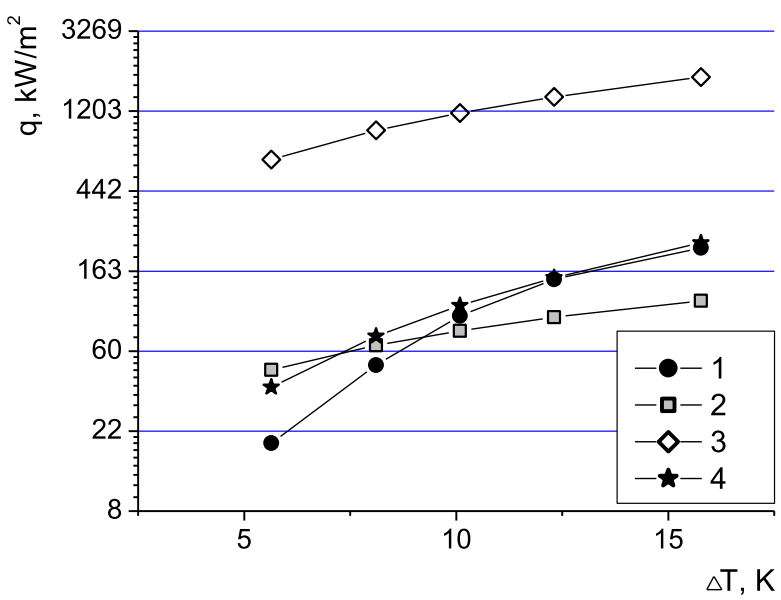

Fig. 12. Comparison of the experimental data (1) with the calculation results according to the correlations: Smirnov et al. (2), Nishikava et al. (3), Xin and Chao (4); bronze mesh $0.20 \mathrm{~mm}$ $\times 0.12 \mathrm{~mm}$, boiling agent: ethyl alcohol.

Based on the data from the above figures, it can be concluded that the best congruence of experimental results for the meshed surface was observed for Xin and Chao model (with certain modifications). It is especially visible for larger superheats - for both working fluids used in the experiments. The least efficient was the model by Nishikava et al. It produced much higher results than those recorded during the experiments - both for distilled water and ethyl alcohol in the whole range of the analysed superheat values.

\section{Conclusions}

Metal meshes sintered onto the heater surfaces can be very effective in providing enhancement of boiling heat transfer. Dissipated heat fluxes might be over seven times higher in relation to the smooth reference surface without any coating. This can be explained by higher density of active nucleation sites present on the heater. It may also be the reason why meshes of smaller aperture values $(0.32 \mathrm{~mm})$ provided better performance than those of larger aperture value $(0.40 \mathrm{~mm})$ - for both boiling agents considered in the present study. However, very dense meshes hamper the conditions of fluid flow during boiling and provide only weak enhancement of heat transfer for large superheats.

The comparison of the experimental results for boiling heat transfer on the meshed surface of aperture $0.20 \mathrm{~mm}$ with correlations taken from literature showed that the most precise model had been proposed by Xin and Chao (with certain modifications) for both working fluids considered in the tests, while the least accurate was the one presented by Nishikava et al.

\section{Nomenclature}

$q \quad$ Heat flux, $\mathrm{kW} \mathrm{m}^{-2}$

$\Delta T$ Superheat, $\mathrm{K}$ 
Acknowledgement. Funding within statutory research of the Faculty of Environmental, Geomatic and Energy Engineering of Kielce University of Technology, No. 05.0.07.00/2.01.01.01.0033 MNSP.IKSI.16.003 is greatly acknowledged.

\section{References}

[1] M.E. Poniewski, Wrzenie pęcherzykowe na rozwiniętych mikropowierzchniach, Wydawnictwo Politechniki Świętokrzyskiej, Kielce, 2001

[2] P. Nemec, A. Caja, R. Lenhard, Analysis of heat transfer limitation of wick heat pipe, in Proceedings of Int. Conf. Experimental Fluid Mechanics 2009, Liberec, Czech Republic, 2009, pp. 229-234

[3] V.Ja. Sasin, V.N. Fedorov, A.Ja. Sorokin, Eksperimentalnoe issledovanie teplovoj trubki na legkokipjaščich teplonositeljach, in Doklady Naučno-Techn. Konf. po Itogam NaučnoIssled. Rabot za 1968-69, MEI, 1969, pp. 79-84

[4] G.F. Smirnov, A.L. Coba, B.A. Afanasiev, The heat transfer by boiling in splits, capilaries, wick structures, AIAA Paper, 461, 1978

[5] S. Hasegawa, R. Echigo, S. Irie, Boiling characteristics and burnout phenomena on heating surface covered with woven screens, J. Nucl. Sci. Technol. 12, 722-724 (1975)

[6] V.I. Tolubinskij, V.A. Antonenko, G.V. Ivanenko, Crisis phenomena in boiling on submerged wire mesh-wrapped wall, Heat Transfer-Soviet Res. 21, 531-535 (1989)

[7] J.Y. Tsay, Y.Y. Yan, T.F. Lin, Enhancement of pool boiling heat transfer in a horizontal water layer through surface roughness and screen coverage, Heat Mass Transfer 32, 17-26 (1996)

[8] A. Brausch, P.A. Kew, Heat transfer mechanisms during the nucleate boiling process from woven mesh screen structures: identification of enhancing and limiting effects, in Proceedings of the 5th Int. Conf. on Boiling Heat Transfer, Montego Bay, Jamaica, 2003

[9] T. Orzechowski, Wymiana ciepła przy wrzeniu na żebrach z mikropowierzchnią strukturalną, Wydawnictwo Politechniki Świętokrzyskiej, Kielce, 2003
[10] C. Li, G.P. Peterson, Evaporation/boiling in thin capillary wicks (II) - effects of volumetric porosity and mesh size, J. Heat Transfer 128, 1320-1328 (2006)

[11] J.-H. Liou, C.-W. Chang, C. Chao, S.-C. Wong, Visualization and thermal resistance measurement for the sintered mesh - wick evaporator in operating flat - plate heat pipes, Int. J. Heat Mass Transfer 53, 1498-1506 (2010)

[12] R. Pastuszko, Pool boiling heat transfer on micro-fins with wire mesh experiments and heat flux prediction, Int. J. Therm. Sci. 125, 197-209 (2018)

[13] M. Piasecka, K. Strak, B. Grabas, Vibration-assisted laser surface texturing and electromachining for the intensification of boiling heat transfer in a minichannel, Arch. Metal. Mater. 62, 1983-1990 (2017)

[14] Ł.J. Orman, Boiling heat transfer on single phosphor bronze and copper mesh microstructures, in T. Vít, P. Dančová, P. Novotný (eds.), Proceedings of Int. Conf. Experimental Fluid Mechanics 2013, Kutná Hora, Czech Republic 2013, pp. 519-522

[15] L. Dąbek, A. Kapjor, Ł.J. Orman, Boiling heat transfer augmentation on surfaces covered with phosphor bronze meshes, in M. Malcho, J. Jandačka, R. Lenhard, K. Kaduchová, R. Nosek, L. Orman, A. Čaja, P. Ďurčanský, M. Holubčík, M. Patsch, P. Pilát, P. Nemec (Eds.), Proceedings of XXI. Int. Conf. The Application of Experimental and Numerical Methods in Fluid Mechanics and Energy 2018, Rajecké Teplice, Slovakia, 2018

[16] G.F. Smirnov, Približennaja teorija teploobmena pri kipenii na poverchnostjach pokrytych kapilljarno - poristymi strukturami, Teploenergetika 9, 77-80 (1977)

[17] G.F. Smirnov, B.A. Afanasiev, Investigation of vaporisation in screen wick - capillary structures, in D.A. Reay (ed.), Proceedings of VI Int. Heat Pipe Conference Advances in Heat Pipe Technology, London, United Kingdom, 1982,

[18] K. Nishikawa, T. Ito, K. Tanaka, Enhanced heat transfer by nucleate boiling on a sintered metal layer, Heat Trans. Jpn. Res. 8, 65-81 (1979)

[19] M.-D. Xin, Y.-D. Chao, Analysis and experiment of boiling heat transfer on t-shaped finned surfaces, Chem. Eng. Commun. 50, 185-199 (1987)

Cite this article as: L. Dąbek, A. Kapjor, Ł.J. Orman, Distilled water and ethyl alcohol boiling heat transfer on selected meshed surfaces, Mechanics \& Industry 20, 701 (2019) 